\title{
Social and psychological training as the communicative competence development tool for future agribusiness specialists
}

\author{
Elena Chubova ${ }^{1, *}$, Svetlana Bylkova ${ }^{1}$ \\ ${ }^{1}$ Don State Technical University, 1, Gagarin square, 344003, Rostov-on-Don, Russia
}

\begin{abstract}
The paper concentrates on studying the structure of the overall development of socio-psychological training which introduces new forms of dialogue and communication in society and all its spheres including education. It is shown that the socio-psychological training can be used as one of the active methods of developing communication skills in a student group. To detail the program objectives, the authors focus on the development of personality through optimizing forms of interpersonal communication. Furthermore, the authors have identified and justified the necessity of applying techniques aimed at the personality as a whole or its individual components to change them according to the training objectives. Emphasis is put on one of the key issues of organizing and conducting the training, namely the question of how to estimate its efficiency. The characteristic features of feedback, which is carried out in the form of conscious control of the communicative interaction of partners and tracking changes in their own behavior, are specified and described. Based on the study, the authors propose to strengthen practical results of the socio-psychological training through including a feedback questionnaire as an assessment tool for the results achieved.
\end{abstract}

\section{Introduction}

Today's reforming of all spheres of education, including higher education, features active convergence of the humanitarian and technical knowledge manifested through implementing new approaches in the real-life context of future professional activities.

In addition to "field-specific" specialists engaged in the production activities, the need arises in the engineers having well-developed managerial abilities, who are apt to coordinate not only work of different production facilities, but also the work teams that fulfill strategic tasks in a certain field of operations. In particular, according to the strategy of sustainable development of rural areas of the Russian Federation by 2030, it is necessary to attract specialists of the radically higher level, namely - highly qualified, active, creative, communicative, able to quickly and efficiently resolve both standard tasks and nonstandard management challenges.

\footnotetext{
* Corresponding author: chubova@list.ru
} 
All of this requires that the academic subjects clearly focused on shaping certain managerial competences are included in the educative route of the agribusiness professionals. Education in engineering that trains future agribusiness workforce purposefully and consistently uses potential of humanitarian knowledge. Inter alia, this need is also dictated by the professional standards developed by employers taking into account relevant requirements of the continuously changing social and economic conditions.

In this article, we will deal with the need to shape and develop such soft skills as efficient interaction with personnel; responsibility and ability to quickly make decisions in difficult situations, which ultimately will enhance efficiency of interpersonal communication in general. The social and psychological training may be considered to be a high-quality tool utilized to reach the set goal.

\section{Materials and Methods}

The training technology holds a unique position among the interactive methods that are actively employed in the modern educative process.

In Russian, the "training" term has several meanings: upbringing, tuition, training course, drilling. Different definitions of training are accounted for by the goals and tasks of the training.

While studying the nature of development of the social and psychological training, one should note in-depth discussion of this subject matter in works of the foreign authors. In particular, the American Society for Training \& Development (ASTD) that unites over 70,000 individual and team members from over 100 countries worldwide has been actively developing trainings of different focus and researching their productivity since 1994. The methodology of the social and psychological trainings was greatly contributed by Manfred Vorwerg. Further evolvement of the social and psychological trainings was facilitated by developments of Carl Ransom Rogers, who created the trainings focused on vital skills for professional qualification of teachers, managers, and consultants. Another example of the group process insight is the group development theory, the theory of using psychological ideas by W. G. Bennis and Herbert A. Shepard that was developed when studying the group interactions.

The group discussion underlies T group practice. In this case, the subject matter of the group discussion covers real interpersonal relations of the group members, and their task is the group itself examining its dynamics through the insight of the processes that take place within it.

Based on the achievements of the foreign researchers, the Russian scholars have continued research of the communicative processes. Thus, E.V. Sidorenko emphasizes the interactivity of the training participants both during the training and interactivity of the actual activities of the training programme participants. [1] Why is it interactivity that is considered by the author as the key factor of the training efficiency? In spite of the unpredictable outcome of the training, the interactivity promotes searching for new routes that are not pre-defined, that is, the training participants can make mistakes thus allowing the training facilitator to develop new knowledge rather than assess, if the task was fulfilled correctly.

According to I.V. Vachkov and S.D. Deryabo, the training may be referred to a special method of obtaining knowledge that allows its participants to learn from their own experience "here and now". What's important is to create the positive psychological atmosphere, where everyone can adequately assess their failures and victories and to understand, what professional skills it is necessary to develop. Taking into account the learning context of the training, neither participant risks the relations and views they 
already have, but acquires and uses new experience. Yu. N. Emelyanov, while defining the "training" term, insists on the fact that it should be used to denote methods of development of the abilities to learn or master any complicated kind of activities, for example, communication.

From the point of view of one of the Russian leading social psychologists L. A. Petrovskaya, the social and psychological training may be treated as the means of psychological impact focused on development of interpersonal communication knowledge, social attitudes, skills and experience.

Summing up the above definitions of the "training" one can conclude that the training refers to the forms of the interactive learning intended to develop the competencies of the interpersonal and professional behavior in the course of communication.

The tasks of the social and psychological training deal with the interpersonal communication and are oriented to development of the personality as the part of the group through optimizing the forms of the interpersonal communication. And the methods used during the training are directly focused on interference in the development of the group or the individual to make certain impact and cause follow-up changes. It deals with the strategic way of improving relations in the group through the changes and realignment of the joint activities. In the most general terms, the social and psychological training is considered as the tool of development of the communicative competence. Another aspect that emphasizes the importance of the set goal is the wide coverage of its participants. [2] These can be representatives of the so called communication-based processions - leaders of different level, teachers, social workers, applied psychologists, and the specialists, whose professional activities include communication as its important component. Another category includes people facing evident communication difficulties, for example, in the industrial collectives (both horizontally - with peers, and vertically - with managers or directs), family relations (whether between spouses or parents and children), other everyday communication (for example, relations with neighbors, friends etc.).

The communicative competence can be improved using certain tools, with the toolkit depending on the interpretation of the communication process itself. Three main components are singled out in the communication structure: communicative exchange, interaction and mutual perception of the communication participants. Thus, we come to understanding that the communicative competence is a complicated multi-aspect concept. Considering the above, the communicative competence of the individual is treated as his / her competence in the interpersonal communication, interpersonal interaction, interpersonal perception. [3]

To get insight into the characteristics of the communicative competence, one should consider the communication process from different perspectives.

At present, the society has quite come to the idea that at least two communication patterns may be distinguished: "subject - object" and "subject - subject". The subject object pattern is actually distilled down to the relations of the manipulator with the manipulated object that are carried out through a variety of regulations - orders, instructions, resolutions, decrees etc. Unlike the above pattern, the subject - subject communication features peer-to-peer psychological positions of the participants, and, therefore, the active position of the subjects, in which either party is not only affected, but also affects the other one. The partners mutually penetrate the feelings and emotional experience of each other, commit to engagement, empathy, mutual acceptance of each other. The subject - subject pattern prevails over the other communication pattern.

While considering the subject - subject relations during the social and psychological training, it can be safely said that these relations are productive due to the in-depth impact on the training participants. Active position of every participant in reaching the ultimate 
outcome of the training process promotes active creative self-efforts and change of the psychological impact.

Modern interpretation of the social and psychological trainings consists in the purposive impact on the group development through optimizing the form of interpersonal communications. As we know, the interpersonal communication can be considered only under the three-pronged concept of the communicative, perceptive and interactive aspects. The social and psychological training is the basis for the entire range of the dedicated trainings, such as negotiations training, sales training, team building, conflict-free behavior training and others.

The objective necessity of the social and psychological development and skills maintenance of the future agribusiness executives of different level is accounted for by heightened requirements to their competence at the modern stage of development of the economy in general and in the agribusiness industry in particular. The most important components of the competence include the readiness of the individual for correct analysis of the moral and psychological climate in the team, which will enable to timely diagnose and overcome the conflict situations taking into account the adequate assessment of their own behavior and behavior of other individuals in the group. The experience shows that nowadays it is not enough for executives to follow only guidelines of the common sense and their own experience when resolving interpersonal issues. Employers set another level of requirements to the specialists in what refers to resolving complicated professional tasks in the uncertain environment or under lack of complete information. Challenges of the modern information society suggest new approaches to the professional competence, development of which is based on the integral professional education experience, convergence of the formal education, successful socialization and certain real-life experience. In the context of the team management (and therefore, impact on the team), one may expect to succeed only with the in-depth scientific knowledge of the nature of the interpersonal communications in the uncertain environment or under lack of complete information.

High requirements to the professional level of executives in what refers to interpersonal relations proceed from the findings of the social and psychological research, according to which the leadership style manifested by executives to their directs to a greater extent determines the character of relations between the employees. In connection with this, it is extremely important to find out the development level of the executive's professional qualities that govern self-perception, perception of the situation, communications partner that can be either an individual employee or a group in general. When developing the social and psychological training programme, one should take into account the high requirements to the communication standards executives should adhere to, their ability to quickly and adequately navigate through the multiple communicative situations.

In terms of the contents, the range of tasks the training tools and methods are employed for is rather diverse, which, in its turn, affects the training classification that generally includes two large classes. The first class includes the trainings oriented to development of specific skills, such as negotiating, discussion skills, resolving interpersonal and group conflicts. The second class of trainings is focused on extending and deepening experience of the insight in the situations of different communication level that deliver experience of self-analysis, analysis of the partner's behavior and the group situation in general. When considering priority of the resolved tasks one should accept shaping and developing social skills and abilities as the top priority since in this case the training programme may be clearly structured and built with the sufficient set of algorithms.

An important advantage of the social and psychological training is creating the situation of immediate inclusion of the obtained information in the activities, emotionally experiencing through new models of behavior and the related outcome. During the training 
a specialist gets feedback to discover the lack of knowledge and skills he or she may have, and finds out whether his or her attitudes and stereotypes are adequate.

Studying the methods of social and psychological trainings one should take into account that, in addition to the traditional methods, such as seminars and conversations, the socalled active learning methods come to the forefront, when the trainee activities become of the productive, creative and explanatory character.

The active learning methods include problem-solving, algorithm-based learning, brainstorming, handling notions outside the context, case study methods etc. In connection with this, there is a sufficient variety of classifications of different training methods, but basically all of them form two large partially intersecting areas - group discussions and games. The group discussion method is used mostly in the form of analysis of certain situations (case study methods) and forms of group self-analysis.

It's worth mentioning that all methods of the social and psychological trainings feature therapeutic effect of the group interaction. Besides, these methods implement the principle of active engagement of training participants through including the research element in learning. The main difference of the active learning methods is that the training participants are focused on obtaining, and to be more exact, generating new knowledge in the course of the training. Besides, the above methods imply specific learning based on certain models that suggest inclusion of the task-solving algorithms. Depending on the set tasks, the above methods may be used individually or jointly.

The modern training programme is based on modules, that is, a set of consecutive, scientifically valid procedures aimed to optimize the training process itself. The name and contents of the module are in line with the tasks and levels of the solved tasks included in the training programme. This way, the personality module is aimed to optimize development and improvement of a personality, while the group module is aimed to optimize development and improvement of a group, and the field-specific module is intended to optimize the processes related with interaction of a personality and a group to solve the training tasks.

The module contents cover methods and techniques focused on the personality as a whole or certain components in order to modify them according to the training tasks. The module may contain several elements aimed to resolve the set tasks, though the emphasis is made on the psychological drills and introspection.

The psychological drills are specific forms of work of the training participants intended to govern their psycho emotional state. As a rule (and there is explanation for that), psychological drills precede the training procedure of the module, which allows to change the state of both its individual participants and the group as a whole. Besides, it's possible to generate the content, understanding and discussion of which may advance meaningfully, and, if required, to adjust the training programme. The set of psychological drills include quite a wide range of task forms, whether written or oral, verbal and non-verbal.

All psychological drills can be classified according to certain criteria (Table 1).

Table 1. Groups of psychological drills.

\begin{tabular}{|c|l|l|l|}
\hline Nos. & \multicolumn{1}{|c|}{ Exercise Group Name } & \multicolumn{1}{c|}{ Objective } & \multicolumn{1}{c|}{ Timing } \\
\hline 1 & $\begin{array}{l}\text { Exercises to establish } \\
\text { contact in communication, } \\
\text { to create performance } \\
\text { capability in the group }\end{array}$ & $\begin{array}{l}\text { They affect the emotional } \\
\text { state of both the group as a } \\
\text { whole and each participant } \\
\text { individually }\end{array}$ & $\begin{array}{l}\text { They are conducted at } \\
\text { the stage of } \\
\text { acquaintance of the } \\
\text { group members }\end{array}$ \\
\hline 2 & Content-driven exercises & $\begin{array}{l}\text { They provide for training } \\
\text { certain techniques, } \\
\text { communication modes, }\end{array}$ & $\begin{array}{l}\text { They take place before } \\
\text { the main stage of the } \\
\text { training }\end{array}$ \\
\hline
\end{tabular}




\begin{tabular}{|l|l|l|l|}
\hline & & behavioral features & \\
\hline 3 & $\begin{array}{l}\text { Personality feedback } \\
\text { exercises }\end{array}$ & $\begin{array}{l}\text { They help evaluate the } \\
\text { training efficiency, make } \\
\text { adjustments on the training } \\
\text { program }\end{array}$ & $\begin{array}{l}\text { They can be carried out } \\
\text { both after the training } \\
\text { and after each stage }\end{array}$ \\
\hline
\end{tabular}

The second mandatory element of the training is introspection aimed at the training participant understanding and comprehending his or her motives, deeds and attitudes, and their possible alteration. Introspection is quite a complicated intellectual activity related with both emotional and appraisal areas. Besides, the introspection also includes a certain share of self-criticism when comprehending the reasons for their actions and thoughts. The introspection can follow up both the training in general and the individual modules. As a result of introspection a person decides, which of the actions of the group and group members were efficient, which were a failure, and whether or not they should be used further. The group introspection is obviously considered to be the most efficient as it is aimed to enhance efficiency of the activities of each group member increasing its potential contribution in reaching the common goals.

One of the key issues of the training management is the way of assessing the training efficiency. Traditionally, the system of internal and external criteria is offered.

Internal criteria are a set of different judgments of the participants about what they have learnt and what skills they have acquired during the training. For this, all kinds of surveys (questionnaires) are used before the training (the so-called input testing) and after it. One should understand that these assessments are of definitely subjective character and can be used as criteria with a certain degree of conditionality. Nevertheless, most efficiency measurements refer to this category.

External criteria are traditionally related with measurements of the perception of the changes that occurred with the training participants, with the people that did not participate in this experience - these can be work or university colleagues, family members etc.

Let us now proceed to consider the training programme as such, namely, its training contents.

Peculiarities of development of the managerial competences of modern executives are related with certain difficulties accounted for by ongoing changes in the society that feature high percentage of uncertainty, high contextuality and the need to make decisions intuitively. The additional difficulty is changes dealing with behavioral settings of the directs, namely, their quick adaptation to any new situation.

Development of the managerial competences becomes ever more difficult due to the fact that it deals with the interpersonal relations, where it is impossible to create definite interaction algorithms what would be applicable to every person. Therefore, communications of people even in the artificially created groups are supposed to facilitate growth of their communicative competence, enhanced efficiency of the managerial activities and as a result - the optimized motivation sphere and growth of an individual.

A student group reasonable fits the context of the social and psychological training due to its interactive character that allows to arrange immediate interaction of the group members in the joint decision-making. In this case, a teacher acts as a facilitator, whose main task is to manage the group relations. Considering certain difficulties of the social and psychological trainings, a teacher is supposed to have a wide range of skills - from the problem-solving and decision-making up to the group management. Efficiency of the facilitator's actions results from his or her integrity and objectivity. Besides, a teacher acting as the facilitator must be aloof "disengaging" his or her personal views and preferences and focusing only on the group dynamics during the training. 
Functionally, the facilitator develops the training programme, its goal and tasks, selects the required techniques and tools aimed to reach the targeted outcome. All developments are recorded and documented. One should also keep in mind that certain adjustments prompted by the specific features of the interpersonal relations in the group may be introduced during the training. Therefore, the results and actions of the participants must be controlled on the ongoing basis in order to timely identify any issues to be resolved.

The discussion format of the discourse for the planned topics underlies any kind of the group activities. In connection with this, the facilitator must structure the discussion process in a certain way taking into account number of the participants. It is allowed to split a large group of participants into smaller "target" sub-groups.

If the case study technologies are used as the active learning method, discussions make take a variety of formats depending on the number of participants. According to I.V. Gladkikh, the case study technologies are focused, to a larger extent, to developing skills and abilities, among which special attention is paid to the ability to process and analyze large data sets.

The problem situation discussion deliverables may be presented by either a representative of the target groups, or all its participants. The main requirements are the structured reasoned statement with the clearly shaped position. This discussion format encourages comprehensive answers to the set questions thus simplifying handling the case study.

The next kind of the discussion implies a group discussion of the problem, where the facilitator deliberately sticks to the wrong position. So the students have either to agree with the suggested solution of the problem, or to argue against it presenting a certain sequence of the facts, conceptual or theoretical information, and their own personal experience.

The discussion, where a teacher offers hypothetical scenarios that go beyond the previously stated positions of the students is considered to be more complicated. In this situation, the competences that ensure efficient collaboration in the group are revealed to the fullest extent possible.

Irrespective of the chosen discussion form, it is necessary to adhere to certain rules, namely, to monitor the activities of every participant; to control the equality of participants when expressing their opinion; to create the democratic atmosphere of interaction between participants.

The final stage of the training includes the feedback that can be provided both at the cognitive, emotional levels and at the level of one's own ideas. The feedback takes the form of the conscious control of the communicative interaction of the partners, the partner observation and follow-up assessment of his or her response, and the monitoring of the changes in one's own behavior. The assessment and perception of the communications partner's actions open the opportunities to adjust one's own behavior as well.

Speaking of the feedback significance, it's important to consider conditions of its efficiency. In this context, the analysis covers peculiarities of the behavior, certain actions in the definite communicative situation, and not the partner's personality. Here, subjective character of the analysis should be taken into account, and therefore it makes sense to present the feedback descriptively, minimizing the judgment statements of the feedback.

\section{Results}

One can enhance the deliverables of the social and psychological training through including the feedback survey as the tool of assessment of the obtained results. When developing surveys one should not include the questions reflecting only the degree of the emotional satisfaction of the participants without revealing other more important and significant changes in their behavior. 
First of all, the feedback survey must be information-bearing, that is, it must contain the required and sufficient material for the teacher to analyze, to what extent the training participants have changed their activities.

We have analyzed multiple final surveys developed and proven by different agencies when holding the social and psychological trainings and have concluded that all survey questions may be grouped in three units:

- closed-end questions;

- open-end questions aimed to assess practical effect of the training;

- open-end questions asking the participants about their assessment of the contents, psychological atmosphere and other aspects of the held training.

Actually, it is allowed to present the third question pool as the self-report that contains opinions, convictions or judgments of the training participants.

Treating the social and psychological training as one of the active learning methods it has been decided to test it for teaching Business Communications academic subject for students studying in the consolidated group with majors of 35.00.00 and 36.00.00.

Before the training, the students were offered input surveys in order to determine the soft skills development level. By results of the training programme, another survey was held, with the following questions included:

- what changes have you introduced in your behavior and what drove the changes (the opinion of other participants, the teacher's judgment, self-analysis);

- what helped (impeded) you during the training;

- what were the new knowledge and skills you have acquired during the past training.

Due to the analysis of the provided answers, the following conclusions were made. Most respondents have mentioned the changes in their own behavior in what refers to the improved ability to control it during interaction with other participants. Besides, the students have specified acquiring the perceptual ability of cognizing themselves and others, which, in their opinion, will improve efficiency of their future professional activities.

Summing up the issues we touched upon that refer to research of the efficiency of the social and psychological training one should note its clear focus on the group development through optimizing the forms of the interpersonal relations. Its primary components that actively affects the end results is the feedback. And here, the key figure is the teacher, who is responsible for setting the trustful communication between all training participants. The social and psychological training is able to resolve the issues arising out of modern challenges of the society development, namely, intensified management activities, extending interpersonal relations and the communication forms becoming ever more complicated.

\section{References}

1. K. Akhtar, International Journal of Humanities and Social Science 2(11), 141-147 (2012)

2. L. Claessens, Teaching and Teacher Education 55, 88-99 (2016)

3. J.A. Cannon-Bowers, C. Bowers, Team development and functioning (American Psychological Association, Washington DC, 2010)

4. Case Method in Practice (Harvard Business School) http://www.hbs.edu/teaching/case-method-in-practice/

5. M. Chávez, A. Roberts, M. Pérez, Advances in Child Development and Behavior 40, 209-241 (2011) http://www.sciencedirect.com/science/article/pii/B97801238649 18000062 
6. H. Heckhausen, J. Heckhausen, Motivation and action (Springer, Cham, 2018) doi:10.1007/978-3-319-65094-4

7. R.R. McCrae, The maturation of personality psychology: Adult personality development and psychological wellbeing (Gerontology Research Center NIA, Baltimore, 2010)

8. R.L. Michalski, T.K. Shackelford, Personality And Individual Differences (Florida Atlantic University, Florida, 2010)

9. H. Özgan, Educational Research and Reviews 11(4), 146-152 (2015) https://files.eric.ed.gov/fulltext/EJ1091526.pdf

10. M.L. Pedditzi, International Journal of School and Cognitive Psychology 1, 114 (2014) doi: $10.4172 / 2469-9837.1000114$

11. A. Russell, R. Webster, P. Blatchford, Maximising the Impact of Teaching Assistants. Guidance for school leaders and teachers (Routledge, 2013)

12. S. Grunwald, A. Hartman, Journal of College Science Teaching 39(3), 28-33 (2010)

13. H.R. Santos-Souza, M.A. Oliveira, Administracao-Ensino E Pesquisa 20(1), 147-183 (2019) https://raep.emnuvens.com.br/raep/article/view/1290

14. E. Winter, P. O'Raw, Literature Review of the Principles and Practices relating to Inclusive. Relating to Inclusive Education for Children with Special Educational Needs (National Council for Special Education, Ireland, 2010) http://ncse.ie/wpcontent/uploads/2014/10/NCSE_Inclusion.pdf 